\title{
Acute reduction of lipolysis reduces adiponectin and IL-18: evidence from an intervention study with acipimox and insulin
}

\author{
B. Lindegaard • S. Ditlevsen $\cdot$ P. Plomgaard • \\ B. Mittendorfer • B. K. Pedersen
}

Received: 8 April 2013 / Accepted: 22 May 2013 / Published online: 29 June 2013

(C) The Author(s) 2013. This article is published with open access at Springerlink.com

\begin{abstract}
Aims/hypothesis Low-grade inflammation is a feature of chronic diseases such as type 2 diabetes and lipodystrophy. It is associated with abdominal adiposity, increased levels of NEFA, hyperinsulinaemia and low adiponectin levels. However, the causal relationship between impaired metabolism and inflammation is not understood. We explored the anti-lipolytic effect of acipimox and insulin on adiponectin and adipocyteassociated cytokines in patients with lipodystrophy.

Methods In a randomised placebo-controlled crossover design using nine patients with non-diabetic, HIV-associated lipodystrophy, we assessed whether (1) overnight administration of a low dose of acipimox and/or (2) insulin-induced suppression of NEFA flux altered circulating plasma levels of adiponectin, IL-18, TNF- $\alpha$ and IL- 6 in the basal condition and in a two-stage euglycaemic-hyperinsulinaemic clamp combined with stable isotopes (insulin infusion rates $20 \mathrm{mU} \mathrm{m}^{-2} \mathrm{~min}^{-1}$ and $50 \mathrm{mU} \mathrm{m}^{-2} \mathrm{~min}^{-1}$ ).

Results Insulin decreased plasma NEFA in a dose-dependent manner $(p<0.0001)$. Acipimox reduced basal plasma NEFAs
\end{abstract}

B. Lindegaard $(\bowtie) \cdot$ P. Plomgaard $\cdot$ B. K. Pedersen

Centre of Inflammation and Metabolism (CIM) 7641,

Rigshospitalet, Blegdamsvej 9, 2100 Copenhagen, Denmark

e-mail: blm@rh.dk

B. Lindegaard · P. Plomgaard · B. K. Pedersen

The Copenhagen Muscle Research Centre, Rigshospitalet,

Copenhagen, Denmark

B. Lindegaard $\cdot$ P. Plomgaard $\cdot$ B. K. Pedersen

Department of Infectious Diseases, Rigshospitalet, Copenhagen, Denmark

S. Ditlevsen

Laboratorium of Applied Statistics, Department of Mathematical

Sciences, University of Copenhagen, Copenhagen, Denmark

B. Mittendorfer

School of Medicine, Washington University, St Louis, MO, USA and plasma NEFAs during the low-dose insulin infusion compared with placebo ( $p<0.0001$ for acipimox effect). Plasma adiponectin and plasma IL-18 were reduced during both situations where lipolysis was inhibited $(p<0.0001$ for acipimox effect; $p<0.0001$ and $p<0.05$ for insulin effect on plasma adiponectin and plasma IL-18, respectively). In contrast, plasma IL-6 and plasma TNF- $\alpha$ did not change during low NEFA concentrations.

Conclusions/interpretation Using two different tools to manipulate lipolysis, the present study found that acute inhibition of lipolysis reduces levels of adiponectin and IL-18 in patients with HIV-associated lipodystrophy.

Keywords Adiponectin · HIV · IL-6 · IL-18 · Inflammation · Insulin resistance $\cdot$ Lipodystrophy $\cdot$ Lipolysis $\cdot$ NEFA $\cdot$ TNF

$\begin{array}{ll}\text { Abbreviations } \\ \text { FOXO1 } & \text { Forkhead box O1 } \\ \text { GPR109A } & \text { G protein-coupled receptor 109A } \\ \text { HAART } & \text { Highly active antiretroviral therapy } \\ \text { NF-kB } & \text { Nuclear factor } \mathrm{kB} \\ \text { PPAR } & \text { Peroxisome proliferator-activated receptor } \\ \text { TLR } & \text { Toll-like receptor }\end{array}$

\section{Introduction}

Systemic low-grade inflammation is thought to play a central role in the development of insulin resistance, leading to type 2 diabetes and cardiovascular diseases [1]. Such inflammation is defined by a two- to threefold increase in circulating cytokines such as TNF- $\alpha$, IL-6 and IL-18. Low-grade inflammation is typically associated with increased levels of NEFA, hyperinsulinaemia, visceral fat accumulation and low adiponectin levels [1]. 
Much attention has been focused on persistent low-grade inflammation in obesity. In the obese state, macrophages are recruited to the adipose tissue. The macrophages subsequently produce cytokines, causing a low-grade inflammatory response [1]. However, the mechanisms that lead to this proinflammatory state are still being investigated.

In obesity, both visceral and subcutaneous fat are sources of systemic low-grade inflammation [2]. Indeed, the distribution of adipose tissue, rather than the total amount of fat, seem to be associated with systemic low-grade inflammation [3-5].

This is illustrated by the lipodystrophy syndrome, where patients lose subcutaneous fat in the limbs and accumulate visceral fat, both of which processes are associated with systemic low-grade inflammation and accompanied by insulin resistance, increased lipolysis and consequently increased levels of NEFA [6]. The most common form of lipodystrophy is the acquired lipodystrophy seen in HIV-infected patients on highly active antiretroviral therapy (HAART) [7].

It is well established that NEFAs promote insulin resistance with compensatory hyperinsulinaemia [8], but NEFAs have also been suggested to be the underlying cause of systemic low-grade inflammation [8]. In support of this, NEFAs are able to engage toll-like receptor (TLR)s, activate nuclear factor $\mathrm{kB}(\mathrm{NF}-\mathrm{kB})$ and induce proinflammatory production of TNF- $\alpha$ and IL-6 [9] at least in vitro. Despite the tight association between increased NEFA levels and systemic inflammation in humans, very few studies in humans have been conducted, and all except for one [10] are based on an endotoxin experimental model [11-15]. Thus it still remains elusive as to whether NEFAs directly influence human cytokine levels in vivo.

While most systemic inflammatory molecules are released from immune cells, adiponectin is released primarily from adipocytes. Low levels of adiponectin are often associated with low-grade inflammation and increased levels of NEFA. Adiponectin has anti-inflammatory effects and decreases circulating NEFAs [16]. Conversely, increased circulating NEFAs decrease circulating adiponectin [17]. It remains unknown whether lowering of NEFA levels regulates adiponectin, as divergent results have been reported from studies using the anti-lipolytic drug acipimox, a nicotinic acid $[10,18-20]$. However, as adiponectin is produced primarily by adipocytes, it can be argued that adiponectin may not sense circulating NEFA levels. Thus, the relationship between adiponectin and circulating NEFA may in fact reflect the possibility that adiponectin and other adipokines are regulated by the anti-lipolytic effect as such. To explore this, we used acipimox and insulin, both of which affect lipolysis through different intracellular pathways. The anti-lipolytic effect of acipimox takes place after the inhibitory regulative G protein action of a G protein-coupled receptor (HM74b), occurring probably with no other effects on the cell and leading to reduced intracellular concentrations of cAMP
$[21,22]$. Insulin also reduces intracellular cAMP, but through a completely different mechanism, namely activation of phosphodiesterases [22]. In addition, insulin exerts its effects via downstream signalling through phosphoinositide 3-kinase, activating, for example, mitogen-activated protein kinase. To better understand the effect on adipokine regulation of inhibiting intracellular lipolysis and lowering systemic NEFA, we explored the in vivo effects of acipimox and insulin on adiponectin and cytokine levels in patients with HIV-associated lipodystrophy. Acipimox and a two-stage euglycaemic-hyperinsulinaemic clamp were used as tools to induce anti-lipolysis, based on our hypothesis that inhibition of lipolysis would inhibit adipokine production and thereby decrease circulating cytokine and adiponectin levels.

\section{Methods}

Participants We recruited nine non-diabetic HIV-positive men on stable HAART from the Outpatient Clinic of the Department of Infectious Disease (Rigshospitalet, Copenhagen, Denmark). A description of selection, anthropometry, HIV-immunology and components of HAART for all participants has been previously published [23]. In brief, the patients were included on the basis of: (1) lipoatrophy (at least one moderate sign of lipoatrophy) [fat loss] in face, arms, buttocks or legs based on a physical examination; and (2) the presence of insulin resistance (fasting plasma insulin $\geq 104 \mathrm{pmol} / \mathrm{l}$ ). If fasting plasma insulin was $<104 \mathrm{pmol} / \mathrm{l}$, a standard $75 \mathrm{~g}$ OGTT was done and the participant included if insulin was $>521 \mathrm{pmol} / 1$ after $120 \mathrm{~min}$. Patient characteristics appear in Table 1.

Informed consent was obtained from all patients according to the requirements of the local Ethics Committee and the Helsinki Declaration.

Design The study was a randomised double-blinded crossover study. Each participant was studied twice at an interval of at least 2 weeks, receiving acipimox on the one occasion and placebo on the other. The HAART medication was taken 3.5 to $4.5 \mathrm{~h}$ before commencing the clamp, with no change to the HAART combination during the study. This enabled us to eliminate the effect of HAART on the cytokine response. Acipimox was administered in doses of $250 \mathrm{mg}$ at 07:00 hours and 24:00 hours (midnight) on the day/night before, and at 07:00 and 09:00 hours on the day of the study. The timing of acipimox treatment and the euglycaemic clamp in relation to fasting was chosen according to previous studies [24, 25]. The study protocol has been described elsewhere [23]. In brief, on each study day, participants reported to the laboratory at 07:00 hours after an overnight fast. Peripheral catheters were inserted into an antecubital vein for blood sampling, in the contralateral antecubital vein for infusion of fluids and in a 
Table 1 Clinical characteristics of the study patients

\begin{tabular}{ll}
$N$ & 9 \\
Age (years) & $52.3 \pm 8.7$ \\
HIV infection duration (years) & 16.3 \\
LogHIV RNA (copies/ml) & $1.90 \pm 1.65$ \\
CD4+ cell counts $($ cells/ $\mu \mathrm{l})$ & $732 \pm 354$ \\
Body weight $(\mathrm{kg})$ & $81.9 \pm 9.6$ \\
BMI $\left(\mathrm{kg} / \mathrm{m}^{2}\right)$ & $25.0 \pm 2.4$ \\
Body fat $(\%)$ & $19.9 \pm 6.6$ \\
Fat mass $(\mathrm{kg})$ & $16.8 \pm 7.2$ \\
Lean body mass $(\mathrm{kg})$ & $62.5 \pm 38.1$ \\
Truncal fat mass $(\mathrm{kg})$ & $10.4 \pm 4.8$ \\
Truncal fat mass $(\%)$ & $60.7 \pm 11.13$ \\
Limb fat mass $(\mathrm{kg})$ & $5.5 \pm 2.85$ \\
Limb fat mass $(\%)$ & $33.4 \pm 10.11$ \\
Trunk:limb ratio & $2.00 \pm 1.08$ \\
Fasting glucose $(\mathrm{mmol} / \mathrm{l})$ & $5.5 \pm 0.69$ \\
Fasting insulin $(\mathrm{pmol} / \mathrm{l})$ & $86 \pm 54$ \\
Fasting triacylglycerol $(\mathrm{mmo} / \mathrm{l})$ & $3.07 \pm 2.22$ \\
Fasting total cholesterol $(\mathrm{mmol} / \mathrm{l})$ & $6.1 \pm 1.4$ \\
Fasting HDL-cholesterol $(\mathrm{mmol} / \mathrm{l})$ & $1.4 \pm 1.05$ \\
Fasting LDL-cholesterol $(\mathrm{mmol} / \mathrm{l})$ & $3.73 \pm 2.22$ \\
Fasting NEFAs $(\mu \mathrm{mol} / \mathrm{l})$ & $412 \pm 183.9$ \\
Fasting TNF- $\alpha(\mathrm{pg} / \mathrm{ml})$ & $1.08(0.95-3.22)$ \\
Fasting IL-18 $(\mathrm{pg} / \mathrm{ml})$ & $304(237-382)$ \\
Fasting IL-6 $(\mathrm{pg} / \mathrm{ml})$ & $2.01(1.68-3.22)$ \\
Fasting adiponectin $(\mu \mathrm{g} / \mathrm{ml})$ & $1.98(1.37-3.03)$ \\
& \\
\hline &
\end{tabular}

Data are mean $\pm \mathrm{SD}$; for cytokines the data are median and $25 \%$ and $75 \%$ quartiles

dorsal hand vein for blood sampling. The hand was wrapped in a heating blanket to obtain arterialised blood samples. After catheterisation, venous blood samples were obtained at 0,30 , 60, 90, 120 and 150 min for measurement of plasma NEFA, and at 0,90 and $150 \mathrm{~min}$ (basal stage) for measurement of cytokine levels. At $2.5 \mathrm{~h}$ later, a two-stage euglycaemichyperinsulinaemic clamp was initiated and continued for $6 \mathrm{~h}$, according to a previously published protocol [26] with some modifications. Insulin (100 IU/ml; Actrapid; Novo Nordisk, Bagsvaerd, Denmark) was infused for $2 \mathrm{~h}$ (stage 1) at a rate of $20 \mathrm{mU} \mathrm{m}^{-2} \mathrm{~min}^{-1}$ (initiated with a two-step priming dose of $80 \mathrm{mU} \mathrm{m}^{-2} \mathrm{~min}^{-1}$ for $5 \mathrm{~min}$, followed by $40 \mathrm{mU} \mathrm{m}^{-2} \mathrm{~min}^{-1}$ for $5 \mathrm{~min}$ ), and for the following $4 \mathrm{~h}$ (stage 2) at a rate of $50 \mathrm{mU}$ $\mathrm{m}^{-2} \mathrm{~min}^{-1}$ (initiated with a two-step priming dose of $200 \mathrm{mU}$ BSA m ${ }^{-2} \mathrm{~min}^{-1}$ for $5 \mathrm{~min}$, followed by $100 \mathrm{mU} \mathrm{m}^{-2} \mathrm{~min}^{-1}$ for $5 \mathrm{~min}$ ). The blood glucose concentration was kept at $5.5 \mathrm{mmol} / 1$ by a variable-rate infusion of $20 \%$ glucose. To maintain euglycaemia, arterialised blood glucose was measured every $5 \mathrm{~min}$ in the first hour of each clamp stage and every $10 \mathrm{~min}$ during the rest of the clamp, with samples being immediately analysed (EML 105; Radiometer, Copenhagen, Denmark).
During the euglycaemic-hyperinsulinaemic clamp, venous blood samples were obtained for measurement of NEFA and cytokine levels at 180, 210, 240 and 270 min during stage 1, and at 300, 330, 390, 450 and $510 \mathrm{~min}$ during stage 2 . As one participant did not complete the clamp study for technical reasons, results during the clamp represent data from eight participants only.

Laboratory analyses All blood samples were drawn into tubes containing EDTA and centrifuged $(3,000 \mathrm{~g})$. Plasma was stored at $-80^{\circ} \mathrm{C}$. Plasma concentrations of IL-18, TNF- $\alpha$, IL- 6 and insulin were determined by ELISA (TNF- $\alpha$ and IL-6: Quantikine High Sensitivity, R\&D Systems, Minneapolis, MN, USA; insulin: DakoCytomation, Ely, UK; IL-18: Medical and Biological Laboratories, Nagoya, Japan). Plasma concentrations of adiponectin were determined by a human adiponectin RIA kit (Linco Research, St Charles, MO, USA). Plasma concentrations of NEFA were determined using an automatic analyser (Cobas fara; Roche, Basel, Switzerland; and NEFA C; Wako Chemicals, Neuss, Germany). The detection limits were $12.5 \mathrm{pg} / \mathrm{ml}$ for IL-18, $0.094 \mathrm{pg} / \mathrm{ml}$ for TNF- $\alpha, 0.18 \mathrm{pg} / \mathrm{ml}$ for IL-6, $0.51 \mathrm{pmol} / 1$ for insulin and $1 \mathrm{ng} / \mathrm{ml}$ for adiponectin. All determinations were run as duplicates and mean values calculated.

Total cholesterol $(\mathrm{mmol} / \mathrm{l})$, HDL-cholesterol $(\mathrm{mmol} / \mathrm{l})$, LDL-cholesterol (mmol/l), triacylglycerol ( $\mathrm{mmol} / \mathrm{l})$ and glucose $(\mathrm{mmol} / \mathrm{l})$ measurements on the day of inclusion were determined using standard laboratory procedures. $\mathrm{CD} 4^{+}$cell counts were calculated by flow cytometry and HIV-RNA copies were measured with an Amplicor HIV Monitor (Roche Molecular Systems, Branchburg, NJ, USA) (lower limit of detection: 20 copies $/ \mathrm{ml})$.

Statistical analysis Values of cytokines, NEFA and insulin were natural log-transformed to achieve homogeneity of variance and an approximate normal distribution. Statistical analyses of the plasma measurements were carried out using a multivariate linear mixed-effects regression model [27]. The effect of treatment was estimated using a binary variable (acipimox or placebo). The effect of insulin infusion was estimated using a categorical variable, i.e. none, low $\left(20 \mathrm{mU} \mathrm{m}^{-2} \mathrm{~min}^{-1}\right)$ or high $\left(50 \mathrm{mU} \mathrm{m}^{-2} \mathrm{~min}^{-1}\right)$ infusion level, with a model that allowed for an interaction term between treatment and insulin infusion when needed. During the insulin infusion, time in minutes was entered as a continuous variable in the analysis of plasma variables, allowing for different effects during low and high insulin infusion, respectively. Thus, the categorical effect variable of insulin models the effect of a different insulin level in plasma, leading to a constant change in the level of the response variable, whereas the time effect during insulin infusion models the cumulative effect over time of a higher insulin level, leading to a rate change in the response variable. A random participant-specific 
component was introduced at the baseline level and allowed adjustment for inter-individual variations. This introduces a positive correlation between measurements from the same participant, while measurements from different participants are independent. The study protocol was designed to measure plasma TNF- $\alpha$, IL-6, IL-18 and adiponectin concentrations from the same individual at several time-points. The statistical models take into account the fact that observations come from the same person [27]. In this way, the total variation is split into the within-participant and between-participant variations, which are known to appear in cytokine response under various stimuli [28], thereby improving the estimation of variables in the study population. Likelihood ratio tests were applied to assess statistical significance. The final model was found by backward stepwise regression. Thus, in the final models, only the terms that were statistically significant were retained. Statistical significance was defined as $p<0.05$. The fit of the general linear model was evaluated by testing the residuals for normality and by inspection of the residual plots. For the analysis, the procedure lme in R (version 2.1) was used [29]. Results are presented as estimates $(95 \% \mathrm{CI})$ if not otherwise stated.

\section{Results}

Baseline characteristics The participants' clinical characteristics are in Table 1. All participants had lipodystrophy as indicated by a decreased percentage of limb fat (limb fat percentage in healthy men 45.3\%) [30] and an increased percentage of trunk fat (trunk fat percentage in healthy men 50.9\%) [30]. The participants had elevated plasma triacylglycerol (value in men with hypertriacylglycerolaemia $>1.7 \mathrm{mmol} / \mathrm{l}$, according to WHO [31]) and NEFA concentrations (value in healthy men $292 \pm 58 \mu \mathrm{mol} / \mathrm{l}$ [mean \pm SEM]) [32]. As an indication of low-grade inflammation, the participants had elevated plasma TNF- $\alpha$ and IL-18 levels, and decreased plasma adiponectin levels (Table 1) compared with cytokine levels in healthy controls obtained in other studies performed in our laboratory (values [median and $25 \%$ and $75 \%$ quartiles] in healthy men: TNF- $\alpha 0.32$ [0.08-0.83] pg/ml [30]; IL-18 111.6 [62.3-171.3] pg/ml [33]; adiponectin 9.10 [4.32-12.05] $\mu \mathrm{g} / \mathrm{ml}$ [30]; IL-6 1.99 [1.45-3.8] pg/ml [30]).

All patients were receiving HAART and at least one nucleoside analogue; seven were receiving at least one protease inhibitor and five a non-nucleoside analogue. All patients except one had suppressed HIV-RNA (HIV-RNA $<18$ copies $/ \mathrm{ml}$ ).

Insulin and glucose concentrations Insulin increased in stage 1 of the euglycaemic-hyperinsulinaemic clamp and increased further in stage 2 of the clamp, while all patients were euglycaemic. Basal plasma glucose and insulin concentrations did not differ between the placebo and acipimox trials [23].

The effect of insulin and acipimox on NEFA concentrations Low doses of insulin reduced plasma NEFA concentrations during stage 1, with no further reduction during high doses of insulin in stage 2 (basal NEFA $431 \mu \mathrm{mol} / \mathrm{l}, p<0.0001$ for main treatment effect; NEFA, end of stage $1232 \mu \mathrm{mol} / 1, p=0.035$ ).

Acipimox reduced basal plasma NEFA concentrations from $431 \mu \mathrm{mol} / \mathrm{l}$ to $209 \mu \mathrm{mol} / \mathrm{l}$. Acipimox and a low dose of insulin infusion decreased plasma NEFA further to $167 \mu \mathrm{mol} / 1$ during stage 1 . This reduction was more pronounced than with insulin alone (placebo) ( $p=0.035$ for interaction between insulin and treatment). Acipimox did not further reduce plasma NEFA during stage $2(p=0.27)$.

The anti-lipolytic effect on adiponectin and cytokines In Fig. 1, geometric means for the plasma concentrations of adiponectin (Fig. 1a), IL-18 (Fig. 1b), IL-6 (Fig. 1c) and TNF- $\alpha$ (Fig. 1d) are shown in the basal state, and at stages 1 and 2. In Fig. 2, the predicted levels of plasma adiponectin (Fig. 2a), plasma IL-18 (Fig. 2b), plasma IL-6 (Fig. 2c) and plasma TNF- $\alpha$ (Fig. 2d) appear as in the final statistical models, i.e. a mixed-effects model. The full model for all four cytokines has four main effects: treatment, insulin, time during stage 1 and time during stage 2 . It has three interaction terms: treatment with insulin, time during stage 1 and time during stage 2 , respectively. The final models were reduced to only retain terms that were significant at a 5\% confidence level.

Plasma adiponectin decreased when lipolysis was inhibited by acipimox and insulin, and consequently plasma NEFA levels were low (Figs 1a and 2a). Acipimox reduced basal plasma adiponectin levels from $2.23 \mu \mathrm{g} / \mathrm{ml}(1.41-3.53)$ to $1.91 \mu \mathrm{g} / \mathrm{ml}(1.12-3.25)$. During stage 1 of the clamp, plasma adiponectin decreased to $1.64 \mu \mathrm{g} / \mathrm{ml}(0.87-3.10)$, decreasing further in stage 2 to $1.48 \mu \mathrm{g} / \mathrm{ml}(0.79-2.79)$. During each stage, the reduction in plasma adiponectin was more pronounced with acipimox than with insulin alone (placebo) ( $p=0.0001$ for main treatment effect).

Insulin reduced basal plasma adiponectin from 2.23 $(1.41-3.53)$ to $1.92(1.1-3.37)$ in stage 1 and further to $1.74(1.0-3.1)$ in stage 2 ( $p<0.0001$ for, main insulin effect).

Plasma IL-18 decreased when lipolysis was inhibited by acipimox and insulin, and consequently plasma NEFA levels were low (Figs $1 \mathrm{~b}$ and $2 \mathrm{~b}$ ). Acipimox reduced basal plasma IL-18 from $310 \mathrm{pg} / \mathrm{ml}$ to $284 \mathrm{pg} / \mathrm{ml}$, with no further reduction of IL-18 occurring ( $p<0.0001$ for main treatment effect). Insulin reduced basal plasma IL-18 from $310 \mathrm{pg} / \mathrm{ml}(248$ $389)$ to $285 \mathrm{pg} / \mathrm{ml}(193-423)$ at the end of stage $2(p=0.023$ for interaction between treatment and time during stage 2 ).

Neither plasma TNF- $\alpha$, nor plasma IL- 6 concentrations responded to the inhibition of lipolysis by acipimox or insulin. In contrast, during stage 1 , insulin actually increased 


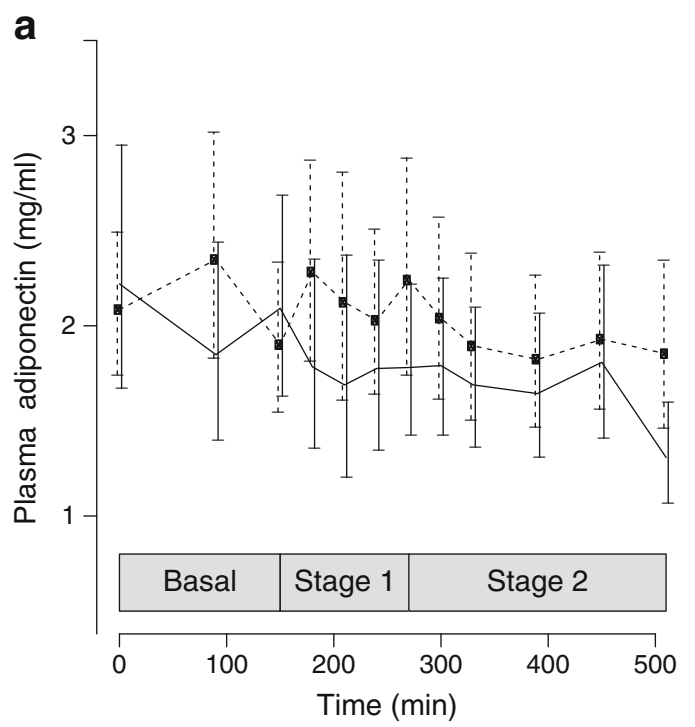

b
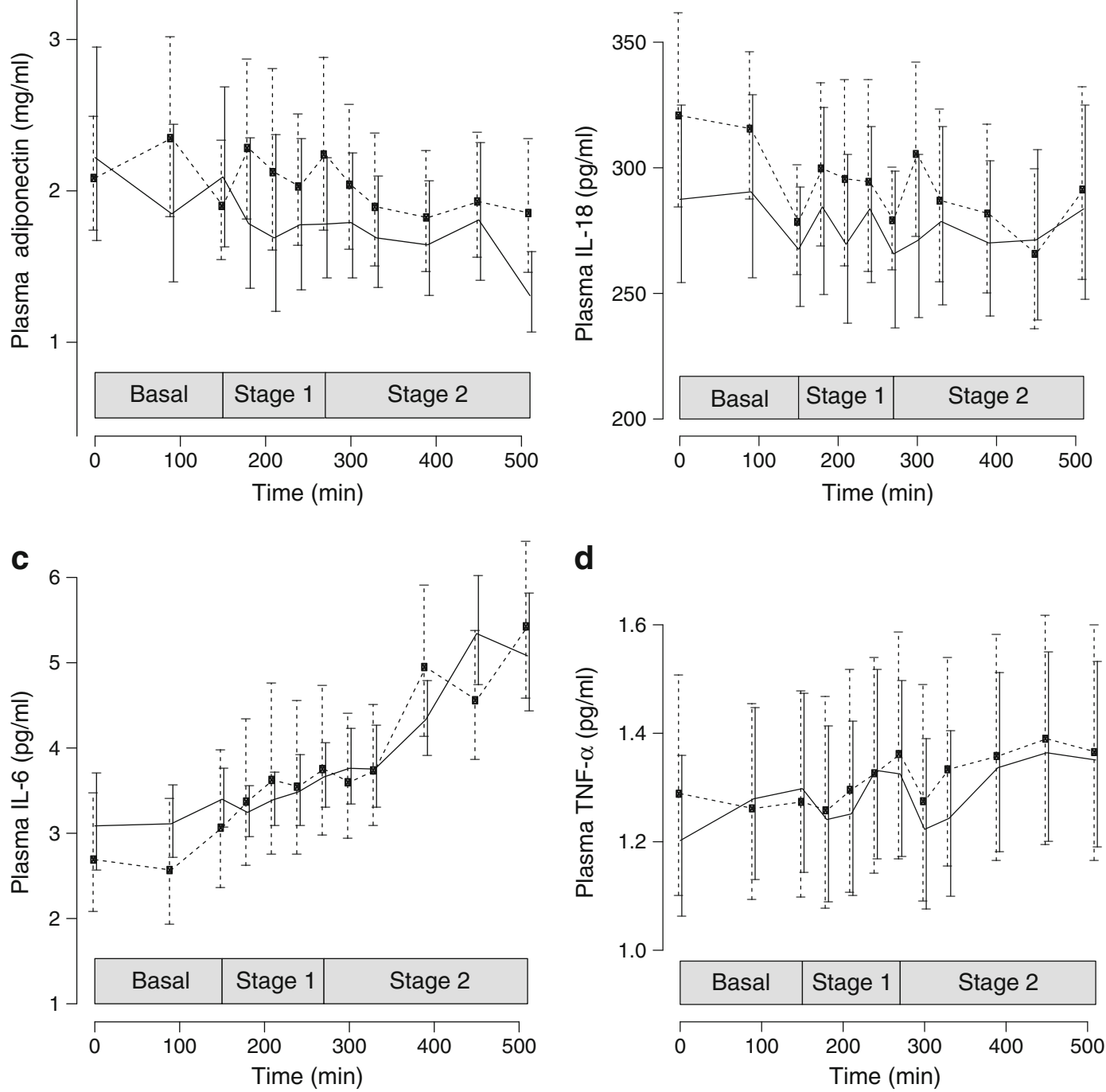

d

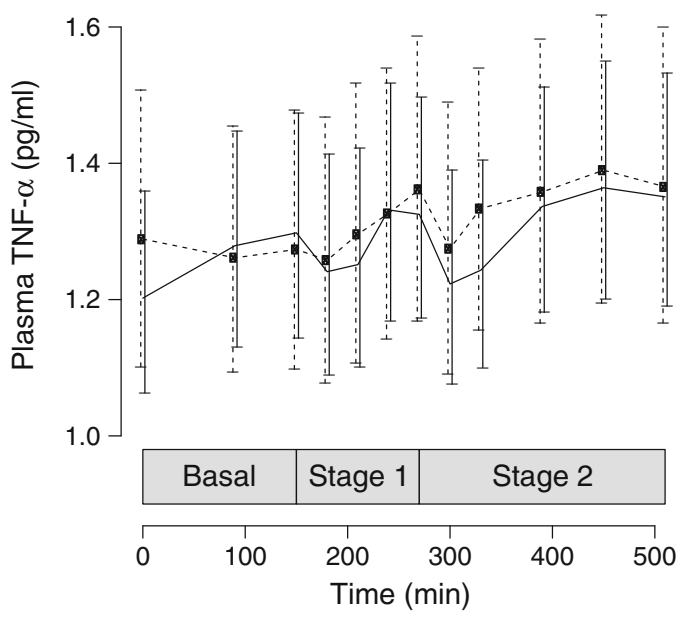

Fig. 1 (a) Geometric means \pm SEM for plasma adiponectin, (b) plasma IL-18, (c) plasma IL-6 and (d) plasma TNF- $\alpha$ levels during the basal stage, low-dose insulin infusion (stage 1) and high-dose insulin infusion (stage 2) after overnight treatment with placebo (dashed lines) and acipimox (solid lines) in nine HIV-infected patients with lipodystrophy. The full statistical model for all four cytokines has four main effects: treatment, insulin, time during stage 1 and time during stage 2 . It has three interaction terms: treatment with insulin, time during stage 1 and time during stage 2 . The final models were reduced to only retain those terms significant at a $5 \%$ confidence level. The statistical results appear as: (1) the effect of acipimox or placebo (treatment, main effect); (2) low or high-dose insulin infusion (insulin, main effect); and (3) time during the different stages of the clamp (time effect); and they allow (4) for an

plasma IL-6 from $2.97 \mathrm{pg} / \mathrm{m}$ to $3.49 \mathrm{pg} / \mathrm{ml}$ (2.31-5.27), with a further increase during stage 2 to $5.41 \mathrm{pg} / \mathrm{ml}(2.79-10.51)$ $(p<0.0001$ for insulin, main effect; $p=0.0001$ for time during stage 2) (Figs 1c and 2c). Similarly, during stage 1, insulin increased basal plasma TNF- $\alpha$ from $1.26 \mathrm{pg} / \mathrm{ml}(0.98-1.62)$ to $1.31 \mathrm{pg} / \mathrm{ml}(0.98-1.76)(p=0.024$ for time during stage 1$)$ with no further increase during stage 2 (Figs $1 \mathrm{~d}$ and $2 \mathrm{~d}$ ).

interaction between treatment, insulin and time. The main effect of treatment was only significant for adiponectin $(p=0.0001)$ (a) and IL-18 $(p<0.0001)(\mathbf{b})$, and was thus removed from the final models of IL-6 (c) and TNF- $\alpha$ (d). Likewise, the main effect of insulin was only significant for adiponectin $(p<0.0001)$ (a) and IL-6 $(p<0.0001)$ (c), and was thus removed from the final models of IL-18 (b) and TNF- $\alpha$ (d). Time was only significant during stage 1 for TNF- $\alpha(p=0.024)(\mathbf{d})$, and during stage 2 for IL-18 $(p=0.046)$ (b) and IL-6 ( $p=0.0001)$ (c). The time effects were removed in all other cases. Only one interaction term was retained, namely the interaction between treatment and time during stage 2 for IL-18 $(p=0.023)$ (b). In total, nine main effects and 11 interaction terms were removed from the final models

\section{Discussion}

In this acute intervention study, lipolysis was inhibited by two completely different methods, acipimox and insulin, in order to investigate the anti-lipolytic effect on systemic levels of adiponectin and cytokines in lipodystrophy patients. The major finding was that acute anti-lipolysis, reflected by a reduction in 

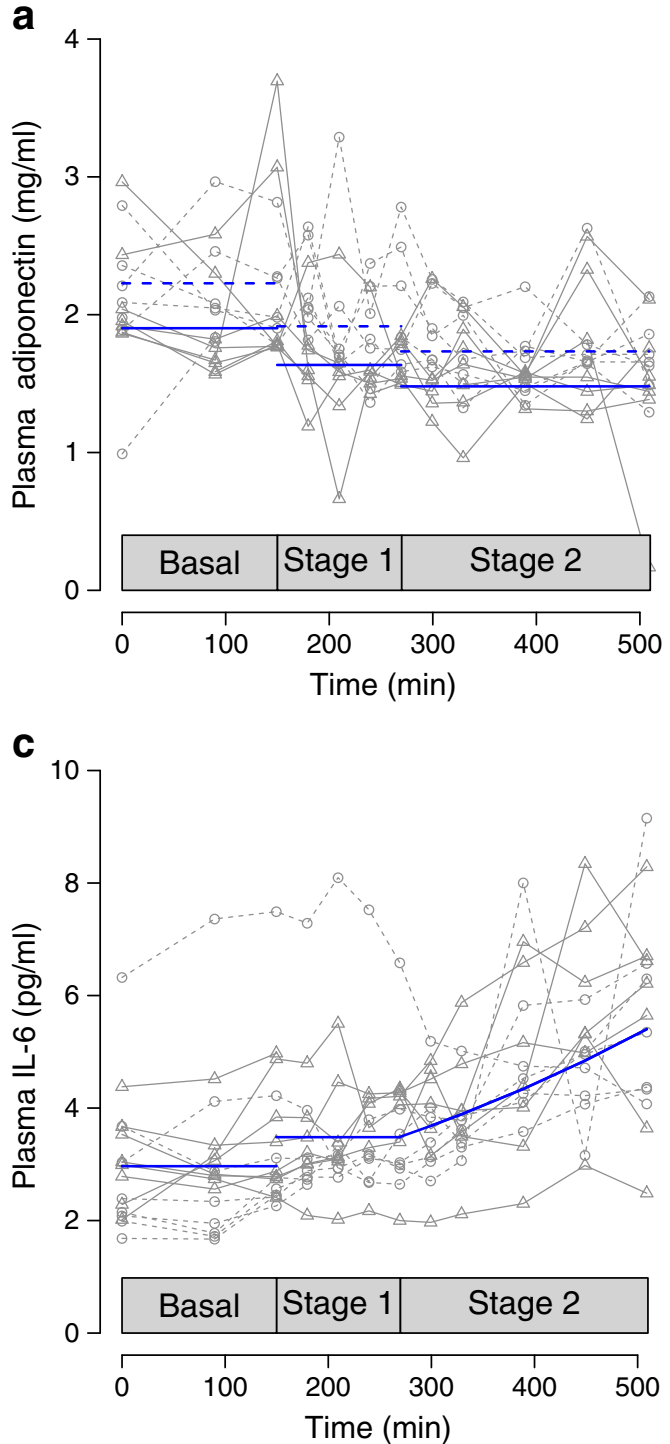

Fig. 2 The predicted levels from the final statistical model of (a) plasma adiponectin, (b) plasma IL-18, (c) plasma IL-6 and (d) plasma TNF- $\alpha$ during the basal stage, low-dose insulin infusion (stage 1) and high-dose insulin infusion (stage 2) after overnight treatment with placebo (blue dashed lines) and acipimox (blue solid lines) in nine HIV-infected patients with lipodystrophy. For IL- 6 and TNF- $\alpha$ the solid lines are predicted values irrespective of treatment status, as no treatment effect was detected. Lines with slopes different from zero indicate a statistically significant cumulative effect of insulin over time beyond the instantaneous effect of a change in insulin infusion. A statistically significant effect of a changed insulin level is shown by discontinuous lines. Note that only one interaction (insulin $\times$ time $\times$ treatment) term was retained, namely for IL-18 during high insulin infusion, where the effect of insulin depends on treatment status. Grey symbols indicate observed values (squares during placebo, triangles during acipimox

NEFA, is sufficient to lower plasma adiponectin and plasma IL-18. This suggests that either intracellular inhibition of lipolysis or reduction of NEFA as such is capable of regulating production and hence circulating levels of adiponectin and IL18. Anti-lipolysis did not influence TNF- $\alpha$ and IL-6 plasma levels; however, hyperinsulinaemia increased circulating IL-6

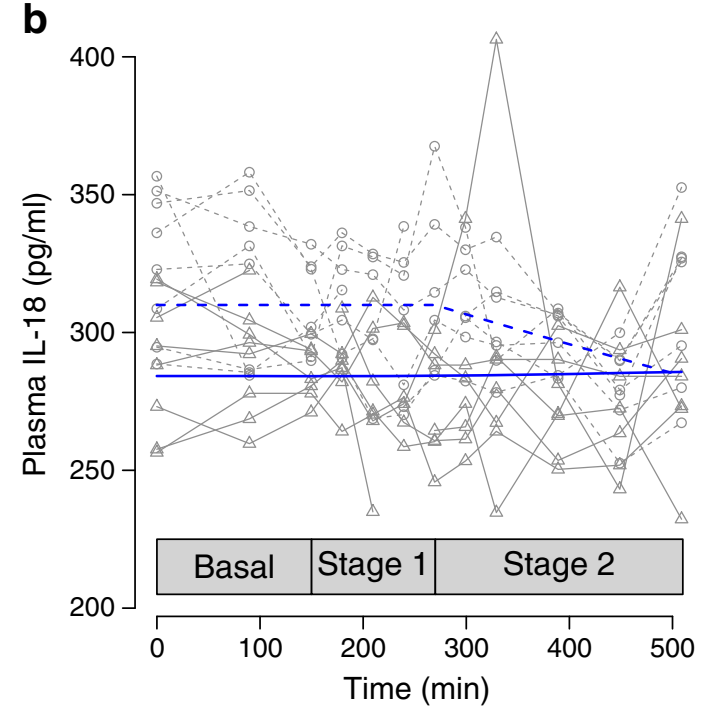

d

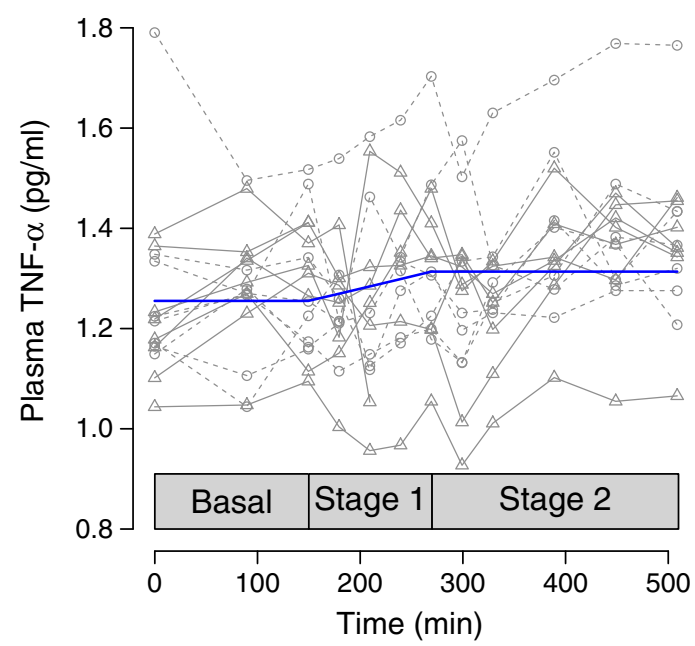

treatment), and grey lines connect measurements from the same participant and day during placebo (dashed grey lines) and during treatment (solid grey lines). The main effect of treatment was only significant for adiponectin $(p=0.0001)$ (a) and IL-18 $(p<0.0001)(\mathbf{b})$, and was thus removed from the final models of IL-6 (c) and TNF- $\alpha(\mathbf{d})$. Similarly, the main effect of insulin was only significant for adiponectin $(p<0.0001)$ (a) and IL-6 $(p<0.0001)(\mathbf{c})$, and was thus removed from the final models of IL-18 (b) and TNF- $\alpha$ (d). Time was only significant during stage 1 for TNF- $\alpha(p=0.024)(\mathbf{d})$, and during stage 2 for IL-18 $(p=0.046)(\mathbf{b})$ and IL-6 $(p=0.0001)(\mathbf{c})$. The time effects were removed in all other cases. Only one interaction term was retained, namely the interaction between treatment and time during stage 2 for IL-18 $(p=0.023)$ (b). In total, nine main effects and 11 interaction terms were removed from the final models

and TNF- $\alpha$ levels, suggesting that insulin, and not NEFA regulates IL-6 and TNF- $\alpha$.

The anti-lipolytic effect on adiponectin Previous studies have found that chronically and acutely elevated NEFA levels suppress adiponectin secretion in vivo [17, 34]. In 
agreement with our hypothesis, we found that intracellular inhibition of lipolysis reduced plasma adiponectin, probably reflecting reduced intracellular production. This result was evident with both forms of lipolysis inhibition, i.e. insulin and acipimox. In agreement with our findings, previous studies using acipimox found a reduction in circulating adiponectin in healthy men with moderate overweight. However, others found [18] no effect in healthy lean participants or in participants with a family history of type 2 diabetes [10,20]. The discrepancy between study results may be explained by the duration of administration (chronically in the study by Bajaj et al [7 days] [10] vs acutely in a study by Bernstein et al [6 h] [18] and in the current study [13 h]) or by the study design (open label administration in Staiger et al [20] vs randomised, placebo-controlled crossover design as in a previous [18] and the present study).

Interestingly, a positive correlation between circulating adiponectin and rate of appearance of glycerol was recently found when correcting for fat mass [17]. It was suggested that circulating adiponectin represents a marker of total adipose tissue lipolytic capacity, a hypothesis that is supported by our results.

We can only speculate on the mechanisms underlying the decrease of adiponectin resulting from inhibition of lipolysis and reduced systemic NEFA levels. Adiponectin gene transcription is stimulated by several factors involved in adipogenesis, e.g. peroxisome proliferator-activated receptor (PPAR) $\gamma$, forkhead box O1 (FOXO1), CCAAT/enhancerbinding protein (C/EBP) alpha, sirtuin 1 and sterol regulatory element-binding protein 1 . It is suppressed by hypoxia, transcription repressors such as nuclear factor of activated $\mathrm{T}$ cells and CREB, and by inflammatory cytokines such as TNF- $\alpha$, IL-6 and IL-18 [16]. As TNF- $\alpha$ and IL-6 did not respond to inhibition of lipolysis, a pathway through TNF- $\alpha$ and IL-6 is unlikely.

NEFAs are directly involved in cellular signalling pathways and regulation of gene transcription, and it has recently been proposed that lipolysis is required to promote PPAR $\gamma$ activated expression of lipogenic genes [22]. When acipimox reduces NEFA, it may lead to reduced PPARG expression, and thereby reduced adiponectin gene expression and reduced circulating adiponectin as seen in our study. This is supported by a previous study, where elevating NEFA in healthy males increased adipose tissue PPARG mRNA levels [35]. Other factors upregulating adiponectin gene transcription such as FOXO1 and sirtuin 1 are inhibited by NEFA in vitro and in mice [36, 37], and may therefore not explain our results, although levels in these former studies were not investigated in an acipimox trial.

Given that insulin and acipimox inhibit lipolysis and lower plasma NEFA levels, it has already been suggested that some effects on gene expression may be shared by nicotinic acid and insulin [38].
As suggested previously, adiponectin may not sense circulating NEFA levels. It has recently been proposed that lipolytic products and intermediates participate in cellular signalling processes [22]. The anti-lipolytic effect of acipimox and insulin takes place through different pathways, leading to reduced intracellular concentrations of cAMP. As insulin and acipimox decreased plasma adiponectin, our findings suggest that the secretion of adiponectin is regulated by anti-lipolytic effect as such.

The anti-lipolytic effect on IL-18 To our knowledge the antilipolytic effect on plasma IL-18 has not previously been examined in vivo. Plasma levels of IL-18 are increased in obesity [39] and lipodystrophy [33], and are associated with several components of the metabolic syndrome, including hypertriacylglycerolaemia [40] and insulin resistance. However, while this suggests that IL-18 is involved in the pathogenesis of insulin resistance [41], IL-18-deficent mice are obese, insulin-resistant and dyslipidaemic compared with wild-type mice [42]. This highlights the complexity of IL18 actions in metabolism.

Our findings revealed that acute anti-lipolysis, resulting in low levels of NEFA, led to reduced amounts of circulating IL-18 and that insulin during acipimox treatment had no additive effect. This suggests that NEFA or lipolytic products, and not insulin as such, regulate systemic IL-18 in vivo. IL-18 secretion is regulated through TLRs. It may therefore be speculated that the regulation of IL-18 by NEFA occurs through engaging TLRs and the induction of NF-KB [9]. Another possibility is through activation of the NLP3 (NLR family pyrin domain-containing 3)-ASC (apoptosisassociated speck-like protein) inflammasome, as NEFAs have recently been found to induce activation of the NLP3ASC inflammasome, causing IL-1 beta and IL-18 production [43]. A previous study found suppression of circulating IL18 during acute hyperinsulinaemia in healthy controls [44], and is thus supported by our data. However, our study adds to the former one in as far as we suggest that the reduction in plasma IL-18 is due to insulin-mediated inhibition of lipolysis. Together, these data suggest that in individuals with insulin resistance, chronically elevated systemic IL-18 may be causally linked to increased plasma NEFA levels and not to hyperinsulinaemia.

In line with the above sentences on the regulation of adiponectin, the regulation of IL-18 may also be related to a drug effect, as the $\mathrm{G}$ protein-coupled receptor 109A (GPR109A) has recently been found to be expressed in immune cells.

The anti-lipolytic effect on TNF- $\alpha$ and IL-6 Several lines of evidence show a relationship between NEFA and inflammation [45]. In addition, NEFAs have been shown to increase TNFA (also known as TNF) expression in adipose tissue [35], 
as well as IL-6 and TNF $\alpha$ secretion in adipocytes [45]. We were therefore surprised that anti-lipolysis and the resultant lowered levels of NEFA with acipimox treatment or insulin did not affect TNF- $\alpha$ and IL-6. Bajaj et al also failed to find an effect of 7 days of acipimox treatment on circulating cytokines [10]. However, this was less surprising as only healthy participants without low-grade inflammation were studied. The discrepancy between our results and the NEFAinduced augmentation of TNFA gene expression in adipose tissue and TNF- $\alpha$ secretion in vitro suggests that NEFAs have local, but no direct systemic effects.

The effect of NEFAs on inflammation has been investigated especially in models where inflammation is induced experimentally by infusion of endotoxin, with additional NEFA infusion enhancing the systemic cytokine response in some [11-13], but not all studies [14, 15]. Some differences between these studies are the observed changes in insulin and glucose concentrations induced by infusion of intralipid. For example, when systemic insulin increases, an enhancement of systemic cytokines occurs [11-13], whereas if insulin concentrations are kept stable with a hyperinsulinaemic-euglycaemic clamp, no effect on the systemic cytokine response occurs $[14,15]$. Thus, as demonstrated in our study, insulin level control is critically important [46]. For instance, upon clamping insulin at levels comparable to those seen in insulin-resistant individuals, we found that insulin (low insulin infusion stage), but not NEFA provoked an acute increase in TNF- $\alpha$ and IL-6, which can be interpreted to mean that while insulin increases systemic IL- 6 and TNF- $\alpha$, plasma NEFAs alone are insufficient to increase IL- 6 and TNF- $\alpha$.

In vitro, acipimox directly reduced the secretion of TNF- $\alpha$ and IL-6 through the GPR109A receptor in human monocytes [47], while in various in vivo animal models, nicotinic acid inhibited vascular inflammation independently of changes in plasma lipids $[48,49]$. However, we found that acipimox had no effect on TNF- $\alpha$ and IL- 6 , and thus acipimox did not regulate those cytokines in our study. Few studies have examined the acute effect of nicotinic acid in humans, and all those that we are aware of investigated the effect after a challenge with endotoxin, inducing very high levels of cytokines [38].

Study limitations Our study has several limitations. One is that it lacks a healthy control group to control for the effect of HAART and immune deficiency. However, the participants acted as their own controls by taking the same antiretroviral medication at 3.5 to $4.5 \mathrm{~h}$ before each clamp on each study day, thereby controlling for the effect of HAART. Furthermore, all patients except one had suppressed HIV-RNA. Our aim, moreover, was to assess the effect of NEFA on inflammatory responses in a patient group with low-grade inflammation rather than in a group of healthy individuals, which has been described elsewhere. Patients with lipodystrophy have increased visceral fat, decreased subcutaneous fat, low- grade inflammation, insulin resistance and excess NEFA. The changes are therefore very similar to those occurring in obesity [50] due to excessive food intake and lack of exercise. Although our study had a small sample size, we found differences between the trials on inflammatory cytokines and adiponectin; it is therefore likely that our results suggest a robust physiological response.

Conclusions Using two different tools to manipulate lipolysis, the present study provides evidence that acute inhibition of lipolysis reduces levels of adiponectin and IL-18 in patients with HIV-associated lipodystrophy.

Acknowledgements We thank the participants for their participation in this study. R. Rousing (The Centre of Inflammation and Metabolism, Rigshospitalet, Denmark), H. Villumsen (The Centre of Inflammation and Metabolism, Rigshospitalet, Denmark), N. Pluszek (The Copenhagen Muscle Research Centre, Rigshospitalet, Denmark) and F. Jessen (The Copenhagen Muscle Research Centre, Rigshospitalet, Denmark) are thanked for excellent technical assistance.

Funding The Centre of Inflammation and Metabolism (CIM) is supported by a grant $(02-512-55)$ from the Danish National Research Foundation. This study was further supported by the Danish Medical Research Council, the Commission of the European Communities (Grant Agreement 223576-:EU FP7 Project: Understanding and combating age-related muscle weakness (MYOAGE)), and by grants from the Danish AIDS Foundation, the Bikuben Foundation, the Illum Foundation, and the Aase and Einar Danielsens Foundation. CIM is part of the Interdisciplinary research initiative at University of Copenhagen (UNIK) project, Food, Fitness and Pharma for Health and Disease, supported by the Danish Ministry of Science, Technology and Innovation. CIM is a member of the Danish Center for Strategic Research in Type 2 Diabetes (Danish Council for Strategic Research, grants 09-067009 and 09-075724). The Copenhagen Muscle Research Centre is supported by a grant from the Capital Region of Denmark. S. Ditlvesen is supported by the Danish Council for Independent Research Natural Sciences.

Duality of interest The authors declare that there is no duality of interest associated with this manuscript.

Contribution statement $\mathrm{BL}, \mathrm{BKP}$ and $\mathrm{BM}$ conceived and designed the study. BL and PP participated in the acquisition of data and the planning of data analyses. SD participated in the planning of analyses, and performed data processing and statistical analyses. BL drafted the article. All authors participated in preparing the analyses and interpreting the data; they also revised the manuscript critically and approved the final manuscript for publication.

Open Access This article is distributed under the terms of the Creative Commons Attribution Noncommercial License which permits any noncommercial use, distribution, and reproduction in any medium, provided the original author(s) and the source are credited.

\section{References}

1. Glass CK, Olefsky JM (2012) Inflammation and lipid signaling in the etiology of insulin resistance. Cell Metab 15:635-645 
2. Fain JN (2010) Release of inflammatory mediators by human adipose tissue is enhanced in obesity and primarily by the nonfat cells: a review. Mediat Inflamm 2010:513948. doi:10.1155/2010/ 513948, Epub;\%2010 May 23.: 513948

3. Fried SK, Bunkin DA, Greenberg AS (1998) Omental and subcutaneous adipose tissues of obese subjects release interleukin-6: depot difference and regulation by glucocorticoid. J Clin Endocrinol Metab 83:847-850

4. Fontana L, Eagon JC, Trujillo ME, Scherer PE, Klein S (2007) Visceral fat adipokine secretion is associated with systemic inflammation in obese humans. Diabetes 56:1010-1013

5. Park HS, Park JY, Yu R (2005) Relationship of obesity and visceral adiposity with serum concentrations of CRP, TNF-alpha and IL-6. Diabetes Res Clin Pract 69:29-35

6. Huang-Doran I, Sleigh A, Rochford JJ, O'Rahilly S, Savage DB (2010) Lipodystrophy: metabolic insights from a rare disorder. J Endocrinol 207:245-255

7. Simha V, Garg A (2006) Lipodystrophy: lessons in lipid and energy metabolism. Curr Opin Lipidol 17:162-169

8. Boden G (2011) Obesity, insulin resistance and free fatty acids. Curr Opin Endocrinol Diabetes Obes 18:139-143

9. Shi H, Kokoeva MV, Inouye K, Tzameli I, Yin H, Flier JS (2006) TLR4 links innate immunity and fatty acid-induced insulin resistance. J Clin Invest 116:3015-3025

10. Bajaj M, Suraamornkul S, Kashyap S, Cusi K, Mandarino L, DeFronzo RA (2004) Sustained reduction in plasma free fatty acid concentration improves insulin action without altering plasma adipocytokine levels in subjects with strong family history of type 2 diabetes. J Clin Endocrinol Metab 89:4649-4655

11. Krogh-Madsen R, Plomgaard P, Akerstrom T, Moller K, Schmitz O, Pedersen BK (2008) Effect of short-term intralipid infusion on the immune response during low-dose endotoxemia in humans. Am J Physiol Endocrinol Metab 294:E371-E379

12. Van der PT, Braxton CC, Coyle SM et al (1995) Effect of hypertriglyceridemia on endotoxin responsiveness in humans. Infect Immun 63:3396-3400

13. Tripathy D, Mohanty P, Dhindsa S et al (2003) Elevation of free fatty acids induces inflammation and impairs vascular reactivity in healthy subjects. Diabetes 52:2882-2887

14. Li X, Ying J, Zeng S et al (2007) A short-term long-chain triglycerides infusion has no influence on immune function of adult patients undergoing gastrointestinal surgery. JPEN 31:167-172

15. Buhl M, Gjedsted J, Granfeldt A et al (2009) Circulating free fatty acids do not contribute to the acute systemic inflammatory response. an experimental study in porcine endotoxaemia. Basic Clin Pharmacol Toxicol 105:319-326

16. Liu M, Liu F (2009) Transcriptional and post-translational regulation of adiponectin. Biochem J 425:41-52

17. Lavoie F, Frisch F, Brassard P et al (2009) Relationship between total and high molecular weight adiponectin levels and plasma nonesterified fatty acid tolerance during enhanced intravascular triacylglycerol lipolysis in men. J Clin Endocrinol Metab 94:998-1004

18. Bernstein EL, Koutkia P, Ljungquist K, Breu J, Canavan B, Grinspoon S (2004) Acute regulation of adiponectin by free fatty acids. Metabolism 53:790-793

19. Dullaart RP, Riemens SC, Meinardi JR, Wolffenbuttel BH, Sluiter WJ (2005) Plasma adiponectin is modestly decreased during 24-hour insulin infusion but not after inhibition of lipolysis by Acipimox. Scand J Clin Lab Invest 65:523-531

20. Staiger H, Tschritter O, Kausch C, Lammers R, Stumvoll M, Haring HU (2002) Human serum adiponectin levels are not under shortterm negative control by free fatty acids in vivo. Horm Metab Res 34:601-603

21. Soga T, Kamohara M, Takasaki J et al (2003) Molecular identification of nicotinic acid receptor. Biochem Biophys Res Commun 303:364-369
22. Zechner R, Zimmermann R, Eichmann TO et al (2012) FAT SIGNALS-lipases and lipolysis in lipid metabolism and signaling. Cell Metab 15:279-291

23. Lindegaard B, Frosig C, Petersen AM et al (2007) Inhibition of lipolysis stimulates peripheral glucose uptake but has no effect on endogenous glucose production in HIV lipodystrophy. Diabetes 56:2070-2077

24. Santomauro AT, Boden G, Silva ME et al (1999) Overnight lowering of free fatty acids with Acipimox improves insulin resistance and glucose tolerance in obese diabetic and nondiabetic subjects. Diabetes 48:1836-1841

25. Fulcher GR, Walker M, Catalano C, Agius L, Alberti KG (1992) Metabolic effects of suppression of nonesterified fatty acid levels with acipimox in obese NIDDM subjects. Diabetes 41:1400-1408

26. DeFronzo RA, Tobin JD, Andres R (1979) Glucose clamp technique: a method for quantifying insulin secretion and resistance. Am J Physiol 237:E214-E223

27. Brown H, Prescott R (1999) Applied mixed models in medicine. John Wiley, Chichester, West Sussex, England

28. Yaqoob P, Newsholme EA, Calder PC (1999) Comparison of cytokine production in cultures of whole human blood and purified mononuclear cells. Cytokine 11:600-605

29. R Development Core Team (2003). R: A language and environment for statistical computing. R Foundation for Statistical Computing. GENERIC, Vienna, Austria

30. Lindegaard B, Keller P, Bruunsgaard H, Gerstoft J, Pedersen BK (2004) Low plasma level of adiponectin is associated with stavudine treatment and lipodystrophy in HIV-infected patients. Clin Exp Immunol 135:273-279

31. National Cholesterol Education Program (NCEP) Expert Panel on Detection EaToHBCiAATPI (2002) Third Report of the National Cholesterol Education Program (NCEP) Expert Panel on Detection, Evaluation, and Treatment of High Blood Cholesterol in Adults (Adult Treatment Panel III) final report. Circulation 106:31433421

32. Mittendorfer B, Horowitz JF, Klein S (2001) Gender differences in lipid and glucose kinetics during short-term fasting. Am J Physiol Endocrinol Metab 281:E1333-E1339

33. Lindegaard B, Hansen A, Gerstoft J, Pedersen B (2004) High plasma level of IL-18 in HIV-infected patients with lipodystrophy. J Acquir Immune Defic Syndr 36(1):588-593

34. Yamauchi T, Kamon J, Waki H et al (2001) The fat-derived hormone adiponectin reverses insulin resistance associated with both lipoatrophy and obesity. Nat Med 7:941-946

35. Nisoli E, Carruba MO, Tonello C, Macor C, Federspil G, Vettor R (2000) Induction of fatty acid translocase/CD36, peroxisome proliferator-activated receptor-gamma2, leptin, uncoupling proteins 2 and 3, and tumor necrosis factor-alpha gene expression in human subcutaneous fat by lipid infusion. Diabetes 49:319-324

36. Yang Z, Kahn BB, Shi H, Xue BZ (2010) Macrophage alphal AMPactivated protein kinase (alpha1AMPK) antagonizes fatty acidinduced inflammation through SIRT1. J Biol Chem 285:1905119059

37. Subauste AR, Burant CF (2007) Role of FoxO1 in FFA-induced oxidative stress in adipocytes. Am J Physiol Endocrinol Metab 293:E159-E164

38. Kang I, Kim SW, Youn JH (2011) Effects of nicotinic acid on gene expression: potential mechanisms and implications for wanted and unwanted effects of the lipid-lowering drug. J Clin Endocrinol Metab 96:3048-3055

39. Esposito K, Pontillo A, Ciotola M et al (2002) Weight loss reduces interleukin-18 levels in obese women. J Clin Endocrinol Metab 87:3864-3866

40. Olusi SO, Al Awadhi A, Abraham M (2003) Relations of serum interleukin 18 levels to serum lipid and glucose concentrations in an apparently healthy adult population. Horm Res 60:29-33 
41. Feve B, Bastard JP (2009) The role of interleukins in insulin resistance and type 2 diabetes mellitus. Nat Rev Endocrinol 5:305-311

42. Netea MG, Joosten LA, Lewis E et al (2006) Deficiency of interleukin-18 in mice leads to hyperphagia, obesity and insulin resistance. Nat Med 12:650-656

43. Wen H, Gris D, Lei Y et al (2011) Fatty acid-induced NLRP3-ASC inflammasome activation interferes with insulin signaling. Nat Immunol 12:408-415

44. Ruotsalainen E, Stancakova A, Vauhkonen I et al (2010) Changes in cytokine levels during acute hyperinsulinemia in offspring of type 2 diabetic subjects. Atherosclerosis 210:536-541

45. Boden G (2006) Fatty acid-induced inflammation and insulin resistance in skeletal muscle and liver. Curr Diabetes Rep 6:177-181

46. Krogh-Madsen R, Plomgaard P, Keller P, Keller C, Pedersen BK (2004) Insulin stimulates interleukin-6 and tumor necrosis factor- alpha gene expression in human subcutaneous adipose tissue. Am J Physiol Endocrinol Metab 286:E234-E238

47. Digby JE, Martinez F, Jefferson A et al (2012) Anti-inflammatory effects of nicotinic acid in human monocytes are mediated by GPR109A dependent mechanisms. Arterioscler Thromb Vasc Biol 32:669-676

48. Wu BJ, Yan L, Charlton F, Witting P, Barter PJ, Rye KA (2010) Evidence that niacin inhibits acute vascular inflammation and improves endothelial dysfunction independent of changes in plasma lipids. Arterioscler Thromb Vasc Biol 30:968-975

49. Lukasova M, Malaval C, Gille A, Kero J, Offermanns S (2011) Nicotinic acid inhibits progression of atherosclerosis in mice through its receptor GPR109A expressed by immune cells. J Clin Invest 121:1163-1173

50. Rochford JJ (2010) Molecular mechanisms controlling human adipose tissue development: insights from monogenic lipodystrophies. Expert Rev Mol Med 12:e24 